\title{
Alexander's Disease and the Story of Louise
}

\author{
Barbara A Wilson ${ }^{1,2}$, Gerhard Florschutz ${ }^{2}$ \& Faraneh Vargha-Khadem ${ }^{3}$ \\ ${ }^{1}$ The Oliver Zangwill Centre; 2. The Raphael Medical Centre 3. UCL Institute of Child \\ Health, and Great Ormond Street Hospital for Children NHS Foundation Trust.
}

\begin{abstract}
We describe the rare condition known as Alexander's Disease or Alexander's Leukodystrophy, which is essentially a childhood dementia. We then present the case of Louise Davies*, a woman who was diagnosed with this disease at the age of 5 years and is still alive at the age of 38 , making her the longest known survivor of this condition. Although now severely impaired, both physically and mentally, and able to do very little, she has lived far longer than expected. We present some neuropsychological results from her childhood before measuring her decline over the past four years. We conclude by considering whether the diagnosis was correct and why she has lived so long.
\end{abstract}

Introduction. In 1949, W.S Alexander, a New Zealand pathologist working in the United Kingdom on a fellowship, reported the case of a 15 month old boy with megalencephaly, hydrocephalus, and psychomotor delays together with progressive degeneration of white matter in the brain and associated intellectual decline (Alexander 1949). During the next 15 years further individuals with a similar pathology were reported (Messing et al 2012). Friede (1964) suggested that these individuals had the same disease and that it should be called after Alexander who first reported the condition. Alexander's Disease or Alexander's Leukodystrophy is a very rare genetic disorder and only about 500 cases world wide have been reported since the first case report in 1949 (Genetics Home Reference 2015). The disease is characterised by abnormal protein deposits known as Rosenthal fibres. These deposits are found mainly in astrocyte (star shaped) cells that support and nourish other cells in the brain and the spinal cord (Alexander 1949; Johnson 1996; Noggle, Dean \& Horton 2012). The disease is one of the leukodystrophies, a group of rare and progressive genetic disorders that affect the central nervous system by disrupting the growth or maintenance of the myelin sheath that insulates nerve cells. Myelin is the fatty covering that insulates nerve fibres and promotes the rapid transmission of nerve impulses. As myelin deteriorates,

* Footnote. We are using Louise's real name with the permission of her mother. 
nervous system functions are impaired.

The disease is inherited in an autosomal dominant pattern. The affected gene is the glial fibrillary acidic protein or GFAP gene (Genetic Home Reference 2015). The following quotation is from the same source.

"Mutations in the GFAP gene cause Alexander disease. The GFAP gene provides instructions for making a protein called glial fibrillary acidic protein. Several molecules of this protein bind together to form intermediate filaments, which provide support and strength to cells. Mutations in the GFAP gene lead to the production of a structurally altered glial fibrillary acidic protein. The altered protein is thought to impair the formation of normal intermediate filaments. As a result, the abnormal glial fibrillary acidic protein likely accumulates in astroglial cells, leading to the formation of Rosenthal fibres, which impair cell function. It is not well understood how impaired astroglial cells contribute to the abnormal formation or maintenance of myelin, leading to the signs and symptoms of Alexander disease".

Brenner et al (2001) report that some $95 \%$ of patients have mutations in the GFAP gene, and no other genetic causes are known. According to Messing et al (2012) there has only been one population-based survey which concluded that there is an incidence of about 1: 2.7 million (Yoshida et al., 2011). Messing et al (2012) believe this figure is an underestimate. The most common classification system suggests there are three main subtypes of Alexander's disease: the infantile form with an onset between birth and two years of age; a juvenile form with an onset between 2 and 12 years; and an adult form with an onset after 12 years of age. The infantile form is the most common and is usually fatal within the first decade of life (Noggle et al 2012). One paper from Japan, however, reports the long term survival of a patient with the infantile form of the disease who is still alive at the age of 25 years and 7 months (Wakabayashi et al 2005). Onset in adulthood is the least common (Pareyson et al 2008). Both the juvenile- and adult-onset forms of the disorder have a slower, more lengthy course compared to the infantile form. For example, Zang et al (2013) followed 22 Chinese children diagnosed with $A D$ and reported that "progression was slower than expected" ( $p$ 183); Iwasaki et al (2015) report a man with the adult onset form who died 11 years after diagnosis.

There is another classification system, however, which suggests there are only two categories of the disorder, type 1 and type 2, depending on the distribution of lesions and clinical features rather than the age of onset (Prust 2011). All type I cases have an early 
onset while type 2 cases can occur at any age. The "early-onset patients typically present with seizures, spasticity, or developmental delays, whereas the later-onset patients more often have signs of hindbrain dysfunction such as ataxia, palatal myoclonus, and dysphagia or dysphonia" (Messing et al 2012: p 5017). Thus Type 1 does not have to show all three symptoms but must demonstrate one of the three.

Neuropsychologists will rarely come across people with this condition. Perhaps the only paper addressing neuropsychological evaluation of affected patients is that of Restrepo et al (2011). They carried out a literature search and could find no accounts of serial neuropsychological testing in patients with confirmed Alexander's Disease. Serial assessments were administered to a young man with the juvenile subtype (he showed the first signs at the age of 9 years but was not diagnosed until early adulthood). He had his first neuropsychological assessment at the age of 15 and was diagnosed with Attention Deficit Hyperactivity Disorder. Two years later he was reassessed due to increasing concerns about his organisational skills and planning behaviour and had a third assessment at the age of 20 . It was at this time that Alexander's Disease was considered and later confirmed through five MRI scans taken between the ages of 9 and 20 years showing progression of white matter degeneration No details of the neuropsychological assessments are provided in the paper.

\section{CASE REPORT}

We report the case of Louise Davies, a woman with Alexander's Disease. Louise was diagnosed at the age of 5 years (the juvenile form) and is still alive at the age of 38 years. We report on early assessments from her childhood before describing the assessments carried out between the ages of 34 and 38 years. These assessments document her decline. We also consider some of the reasons why she has lived longer than expected.

\section{Louise Davies Background.}

Born in 1977, Louise had a normal birth. She weighed just over seven pounds and thrived despite the fact that she suffered from projectile vomiting. Her development, however, was always slightly delayed. For example, she did not walk until she was 18 months old. After 21 months, Louise's younger sister was born. She has always been well and has recently become a mother. When Louise was three years old, she went to nursery school. Her development continued to be slow but she achieved all her milestones eventually.

Between the ages of four and five years, Louise lost weight. She was still vomiting so her mother thought, initially, this was the cause of the weight loss. She took her daughter to the 
general practitioner who referred her to Kings College Hospital in London. A urine specimen was required but Louise refused to perform. The family left with no diagnosis as to the cause of the little girl's problems. Eventually some friends collected money to have Louise seen by a private doctor in Harley Street who said that Louise was a very sick little girl. He referred her to Great Ormond Street Hospital (GOSH), a specialist children's hospital in London. Louise was now just five years old. When seen at GOSH, the family was told that Louise was to be admitted for five days to find out what was wrong. She was there for three months! She had many diagnostic examinations and eventually a diagnosis of probable Alexander's Leukodystrophy was made. It was "probable" because in order for the diagnosis to be definite, her progress needed to be monitored. All hospital records since then have accepted the diagnosis of Alexander's Disease. When told of the diagnosis, Louise's mother asked if that meant an operation was needed and was told that nothing could be done and Louise would die.

Louise managed quite well for a few years, apart from continued and frequent vomiting. She even vomited in her sleep. She attended mainstream school from age five to ten years. The family then moved house and settled close to a special school for delicate children. After an assessment by an educational psychologist, the school accepted Louise and she stayed there until she was 16 years old. Despite the chronological age of 16 , her mother felt Louise was more like an eight year old in her behaviour. After leaving school, Louise went to a special college for pupils with a disability for two years, before being sent to a sheltered workshop near her home.

There were times during her childhood when Louise stopped vomiting and put on weight, she would plateau and then go backwards again. This became a familiar patternSoon after this, in 2000 , her mother had a call to say that Louise had been admitted to hospital with either a stroke or a seizure. Until that time Louise had walked but she never walked again following the hospital admission. It was after this event that Louise was admitted to the Raphael Medical Centre (RMC) where she has been ever since. In 2013, while at the RMC, she had a seizure lasting for one hour and was admitted to hospital for several weeks. She deteriorated yet again. Unsurprisingly, there has been a steady decline over the years. Louise no longer knows her mother, she no longer speaks and rarely smiles. Her decline over a three-year period is documented in her neuropsychological assessments detailed below.

\section{Brain Imaging}


Unfortunately, we have been unable to track down the early scans. A CT scan in 2010, when Louise was 33 years old, showed generalised atrophy with thickening of the frontal bones and low density within the deep white matter bilaterally. Another CT scan was carried out in 2013. The report said that the head was rotated contributing to the assymetry of the image there was extensive, and severe white matter atrophy and low density changes. The scan of 2013 was compared to that of 2010 , and the report indicated that the abnormality had further progressed particularly in the frontal lobes. There was also a comment about the dilatation of the ventricular system especially the lateral ventricles. The cerebellar white matter was grossly atrophic and there was marked atrophy of the brain stem structures. No new lesions were seen.

Figures 1a \& 1b show relevant slices of the 2013 scan.

\section{Neuropsychological Assessments}

During her childhood, Louise was assessed at GOSH. Initially she was tested with the Kaufman Assessment Battery for Children (Kaufman \& Kaufman 1983). At that time, her performance indicated she had mild special educational needs. She was reassessed in 1991 (at the age of 14 years) with the Wechsler Intelligence Scale for Children - Revised (Wechsler 1974). Her verbal IQ then was estimated to be 65 , her performance IQ was estimated to be 63 and her full scale IQ, 60. These results are consistent with the ones reported several years before, suggesting that Louise remained with mild/moderate special educational needs. The report dated September 1991 indicated that Louise was functioning well below her chronological age. She was seen once more by a clinical psychologist in 1993 at the age of 16 years, just before her discharge from GOSH. No formal tests were administered at this time as the psychologist felt that Louise's competence was best judged by looking at her independence in everyday living skills rather than her academic status.

Louise was admitted to the RMC in 2000 but was not formally seen for a neuropsychological assessment until 2012.

(1) The first neuropsychological assessment at the RMC was carried out in January 2012.

Louise was seen on three occasions. She was in a wheelchair, her speech was dysarthric, quiet and hard to understand. She had a simple communication board that she did not use. She sometimes used a "thumbs up" sign for "Yes" and a "thumbs down" for "No" but was often reluctant to do this and tried to communicate through speech. Although her speech 
was clear on some occasions, it was not always possible to understand her. She mostly used one word answers to questions. Four tests were administered. The first was the Wessex Head Injury Matrix (WHIM: Shiel et al 2000). This is a behavioural observation assessment tool. It consists of 62-items in a roughly hierarchical order from 'least to most difficult', providing a sequential framework for behaviour covering a patient's level of responsiveness and interaction with the environment. The second test was the Middlesex Elderly Assessment of Mental State (MEAMS: Golding 1988). Although this screening test is meant for older people, it is comprised of 12 very simple sub tests enabling patients of all ages to participate and, in many cases, achieve a score. The third test was the Putney Auditory Comprehension Screening Test (PACST: Beaumont et al 2002). This is comprised of 60 yes/no questions. The participant has to indicate (in any way possible) whether the answer is "yes" or "no". It was designed to improve the assessment of auditory comprehension for patients with severe physical disability such as that found in some cases of advanced multiple sclerosis, Huntington's disease, brain injury and brainstem stroke. The fourth test was Spot the Word (Baddeley, Emslie and Nimmo-Smith 1993). This is a measure for estimating premorbid cognitive abilities. Participants are presented with pairs of items comprised of one word and one nonword. The goal is to identify the real word in each pair. Louise failed all items on the MEAMS; the Spot-the-Word test was abandoned as she made many errors on the practice items. She scored, however, on the WHIM where 37 from a total of 62 behaviours were observed. The highest ranked behaviour was 52 (uses one or two gestures). On the PACST, Louise was able to answer all four practice items correctly; of the 60 questions in the test she answered 47 correctly. This is in the impaired range but above chance.

The conclusions at that time were

1. Miss Davies is alert and able to concentrate for short periods.

2. She is sociable and tries to communicate. She smiles readily.

3. She has some understanding of true/false sentences but makes frequent errors

4. She can read and write her own name

5. She is not oriented to time or place

6. She has poor recognition memory

7. Her basic perceptual ability seems reasonable. 
(2) Louise was assessed again in 2013 just after her return from hospital (where she was admitted because of a prolonged seizure). It was noted that her behaviour had changed, she appeared to be fearful when she first arrived in the neuropsychologist's office and she cried. She soon quietened down and seemed to be reassured. She was less friendly and sociable than before and had much less speech (the only sound heard was a low moaning sound). She could not be persuaded to use a thumb up for "Yes" and a thumb down for "No". She smiled only once and was more withdrawn than when seen the previous year.

The WHIM and the PACST were re-administered. Louise's scores had declined on both tests. The total number of behaviours observed on the WHIM was 24 with the highest ranked behaviour being 43 (smiles). The PACST was abandoned because her "Yes/No" responses were unclear. On one occasion she shook her head for "No" and on another tried a thumb up for "Yes" but mostly she made the same low moaning sound for all responses. It is probable that she passed the 4 practice items but this was unclear.

The conclusions this time were

(a) Miss Davies' cognitive functioning would appear to have declined since last seen.

(b) Her scores on the WHIM were lower this time. They were also lower on a comprehension test, where yes/no responses were required.

(c) She was no longer able to write her own name or to point to the correct spelling of her first name.

(d) She was also less sociable and more withdrawn than when previously seen.

(3) The third assessment took place in 2014. Louise did not cry but looked sad and seemed to need frequent reassurance. She blinked when asked but was not able to blink once for "yes" and twice for "no". It was not possible to establish a reliable "yes/no" response. Although her highest score on the WHIM was 43 (smiles) the same as the previous assessment, her total score was lower at 21 . She was unable to participate in the PACST. The conclusion was that she had declined a little further.

(4) The fourth assessment was carried out in 2015. Louise was awake and made the same moaning sound as before. Her highest recorded score on the WHIM was 14 (mechanical vocalisation) and the total number of behaviours observed was 8 suggesting even further decline. 
(5) The final assessment was carried out in 2016. Once again, the highest recorded score was 14 (mechanical vocalisation), while the total number of behaviours observed was 7 , slightly less than before.

. A summary of Louise's WHIM results can be seen in Table 1

TABLE 1 ABOUT HERE

\section{Discussion}

We provide the case history of Louise Davies, diagnosed with "probable Alexander's Leukodystophy" in 1982 at the age of 5 years, identifying the type of the disorder as the juvenile onset subtype. We recount her early days, how the family learned of the diagnosis, her schooling and her decline particularly over the past four years. Although now very impaired, Louise is still alive at the age of 38 years.

Perhaps two main questions arise from this study: first did Louise really have Alexander's Disease, and second why did she live so long?

To address the first question: several papers indicate that the diagnosis is strongly suggested by MRI findings (Van der Knaap et al., 2001, 2005; Pareyson et al 2008; Restrepo et al 2011). Messing et al (2012) report that "diagnosis is usually suspected based on characteristic appearances on MRI, with a frontal leukodystrophy common in the younger patients and a hindbrain predominance of lesions, sometimes with atrophy of the medulla oblongata and cervical spinal cord, in the later onset patients" (5018). This fits very well with the reports from the scans of Louise's brain, albeit the scans were CT rather than MRI. Specifically, frontal lobe thickening was commented on in both the 2010 and the 2013 CT scans consistent with Messing et al's (2012) findings. The 2013 scan also mentioned gross atrophy in the cerebellar white matter and marked atrophy of the brain stem structures. Damage was also seen in the region of the medulla oblongata. With regard to the other classification systems, namely type 1 and type 2, Messing et al (2012) report that type 1 , is typically of early onset begining with seizures, spasticity, or developmental delays. Louise was certainly developmentally delayed. Her young age and slow decline is also strongly indicative of Alexander's Disease.

To return to the second question, why did Louise live so long, there are probably several reasons. Her physical care for the past 16 years has been excellent which has, no doubt, been partially responsible for her longevity. In addition, we know that the juvenile forms of 
the disorder show a slower rate of decline than the infantile forms. Indeed, there is even one case reported of a 25 year old woman previously diagnosed with the juvenile form of the disease who went into spontaneous remission (Namekawa et al 2012). Zang et al (2013), in their follow up of 22 Chinese children, indicate that decline in their sample was slower than expected. So, although Louise is unusual in as much as she has lived so long (and longer than any other person diagnosed with the juvenile form as far as we can tell), it is perhaps just within the normal range for people with juvenile onset Alexander's Leukodystrophy.

\section{Conclusions}

We describe the characteristic features of Alexander's Disease, a childhood form of dementia, and provide details of Louise, a 38 year old woman, diagnosed with the juvenile form of the disorder when she was 5 years old. She would appear to be one of the longest living individuals diagnosed at a young age. We suggest that good physical care together with the fact that the juvenile form shows a slower rate of decline than the infant onset form, is responsible for her long life.

\section{References}

Alexander, W. S. (1949). Progressive fibrinoid degeneration of fibrillary astrocytes associated with mental retardation in a hydrocephalic infant. Brain $\underline{72}$, 373-381.

Baddeley A.D, Emslie H,C \& Nimmo-Smith I (1993) The Spot-the-Word test: A robust estimate of verbal intelligence based on lexical decision British Journal of Clinical Psychology, 32 pp. 55-65

Beaumont J.G, Marjoribanks J, Flury S \& Lintern T, (2002) Putney Auditory Comprehension Screening Test (PACST) London: Harcourt Assessment

Brenner M, Johnson A.B, Boespflug-Tanguy O, Rodriguez D, Goldman J.E \& Messing A (2001) Mutations in GFAP, encoding glial fibrillary acidic protein, are associated with Alexander disease. Nat Genet 27:117-120. 
Genetics Home Reference www. ghr.nlm.nih.gov/condition/alexander-disease downloaded December 2015

Golding E (1988). Middlesex Elderly Assessment of Mental State. Bury St Edmunds; Thames Valley Test Company; 1988.

Iwasaki Y, Saito Y, Mori K, Ito M, Mimuro M, Aiba I, Saito K, Mizuta I, Yoshida T, Nakagawa M, Yoshida M (2015). An autopsied case of adult-onset bulbospinalform Alexander disease with a novel S393R mutation in the GFAP gene. Clin Neuropathol. 34(4):207-14. doi: 10.5414/NP300806.

Johnson AB (1996) Alexander disease. In: Moser HG (ed) Handbook of clinical neurology. Vol 22. Neurodystrophies and neurolipidoses. Elsevier, Amsterdam, pp 701-710 Johnson, A. B. and Bettica, A. (1989). On-grid immunogold labeling of glial intermediate filaments in epoxy-embedded tissue. Am. J. Anat. 185, 335341.

Kaufman, A.S., \& Kaufman, N.L. (1983). Kaufman Assessment Battery for Children. Circle Pines, MN: American Guidance Service.

Messing, A., Brenner, M., Feany, M. B., Nedergaard, M., \& Goldman, J. E. (2012). Alexander disease. The Journal of Neuroscience, 32(15), 5017-5023.

Namekawa M, Takiyama Y, Honda J, Sakoe K, Naoi T, Shimazaki H, Yamagata T, . Momoi M.Y and Nakanol. (2012) A novel adult case of juvenile-onset Alexander disease: complete remission of neurological symptoms for over 12 years, despite insidiously progressive cervicomedullary atrophy. Neurol Sci 33 1389- 1392

Noggle C.A., Dean R.S., Horton Jr A.M. (eds) The Encyclopedia of Neuropsychological Disorders. (2012) New York: Springer Publishing Company xxiii \& 804

Pareyson D ${ }^{1}$, Fancellu R, Mariotti C, Romano S, Salmaggi A, Carella F, Girotti F, Gattellaro G, Carriero MR, Farina L, Ceccherini I, Savoiardo M. (2008) Adult-onset Alexander disease: a series of eleven unrelated cases with review of the literature Brain 131 :2321-31. doi: 10.1093/brain/awn178.

Prust $\mathrm{M}^{1}$, Wang J, Morizono H, Messing A, Brenner M, Gordon E, Hartka T, Sokohl A, Schiffmann R, Gordish-Dressman H, Albin R, Amartino H, Brockman K, Dinopoulos A, Dotti 
MT, Fain D, Fernandez R, Ferreira J, Fleming J, Gill D, Griebel M, Heilstedt H, Kaplan P, Lewis

D, Nakagawa M, Pedersen R, Reddy A, Sawaishi Y, Schneider M, Sherr E, Takiyama Y, Wakabayashi K, Gorospe JR, Vanderver A (2011) GFAP mutations, age at onset, and clinical subtypes in Alexander disease Neurology.77(13):1287-94. doi:

10.1212/WNL.0b013e3182309f72. Epub 2011 Sep 14.

Restrepo J, Bernardin L, Hammeke T (2011). Neurocognitive decline in Alexander disease. Clin Neuropsychol. 2011 25(7):1266-77. doi: 10.1080/13854046.2011.604043. Epub 2011 Sep 9.

Shiel, A., Wilson, B.A., McLellan, L., Horn, S., \& Watson, M. (2000). The Wessex Head Injury Matrix (WHIM). Bury St Edmunds: Thames Valley Test Company.

Wakabayashi K, Lai M, Masuko K, Yamashita S, Yamada M, Iwamoto H, Aida N, Shiroma N, Kanazawa N, Tsujino S. (2005) A case of long-term survival of a patient with infantile Alexander disease diagnosed by DNA analysis. No To Hattatsu. 37 :55-9.

Yoshida, T., Sasaki, M., Yoshida, M., Namekawa, M., Okamoto, Y., Tsujino, S., ... \& Alexander Disease Study Group in Japan. (2011). Nationwide survey of Alexander disease in Japan and proposed new guidelines for diagnosis. Journal of neurology, 258(11), 1998-2008.

Wechsler, D. (1974). Manual for the Wechsler Intelligence Scale for Children-Revised. New York: Psychological Corporation

Zang L, Wang J, Jiang Y, Gu Q, Gao Z, Yang Y, Xiao J, Wu Y (2013) Follow-up study of 22 Chinese children with Alexander disease and analysis of parental origin of de novo GFAP mutations J Hum Genet. 58 183-8. doi: 10.1038/jhg.2012.152. Epub 2013 Jan 31

\section{FIGURE}

\section{FIGURE ONE A \& ONE B}

A CT SCAN CARRIED OUT IN 2013:

Figure $1 \mathrm{~A}$ shows the rotation of the head causing the assymetry of the scan and the atrophic cerebellar white matter and brain stem structures. 


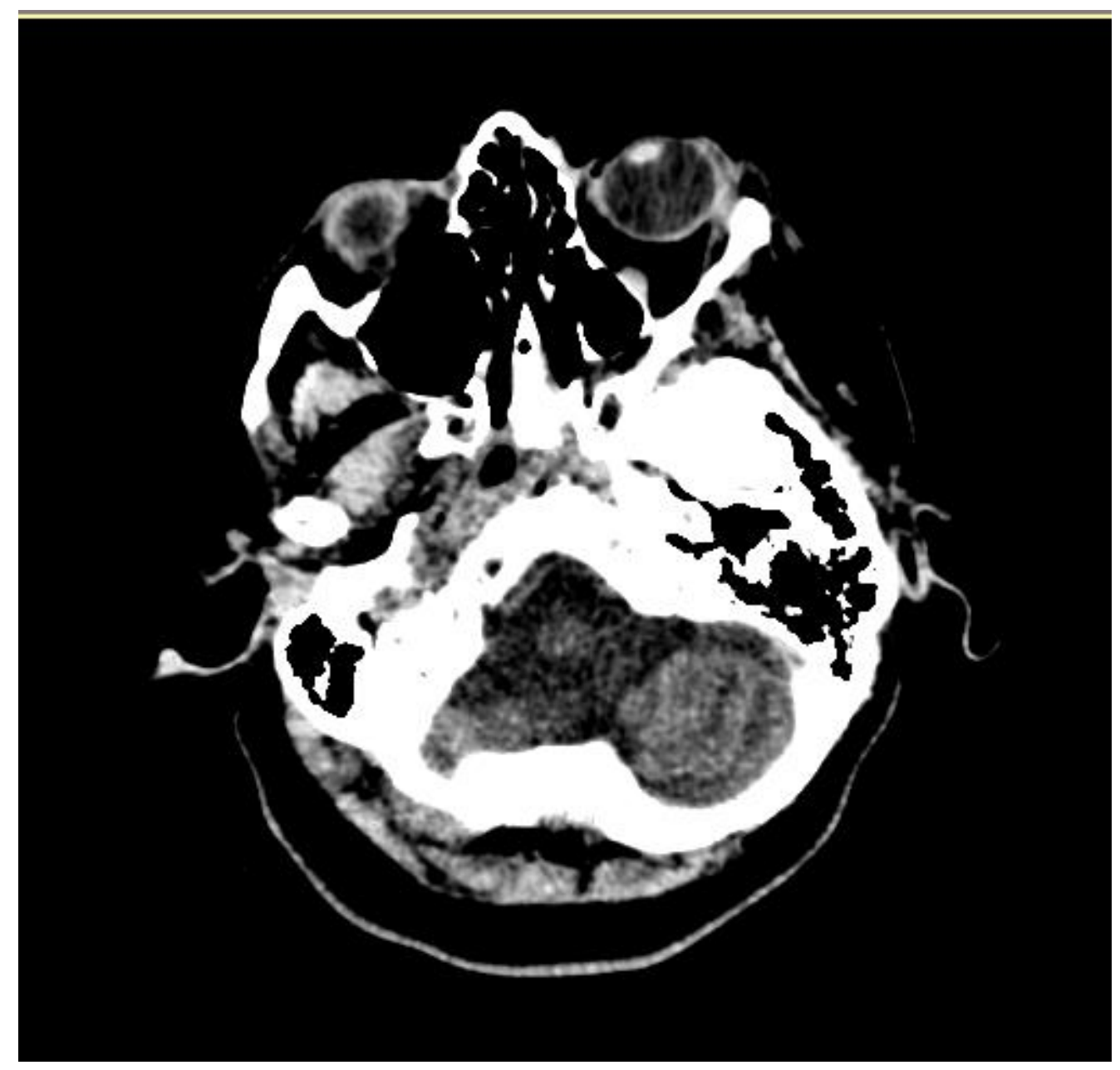

Figure $1 \mathrm{~B}$ shows the thickening of the skull, the dilation of the ventricles and the cortical atrophy with relative sparing of the parietal and occipital lobes. 


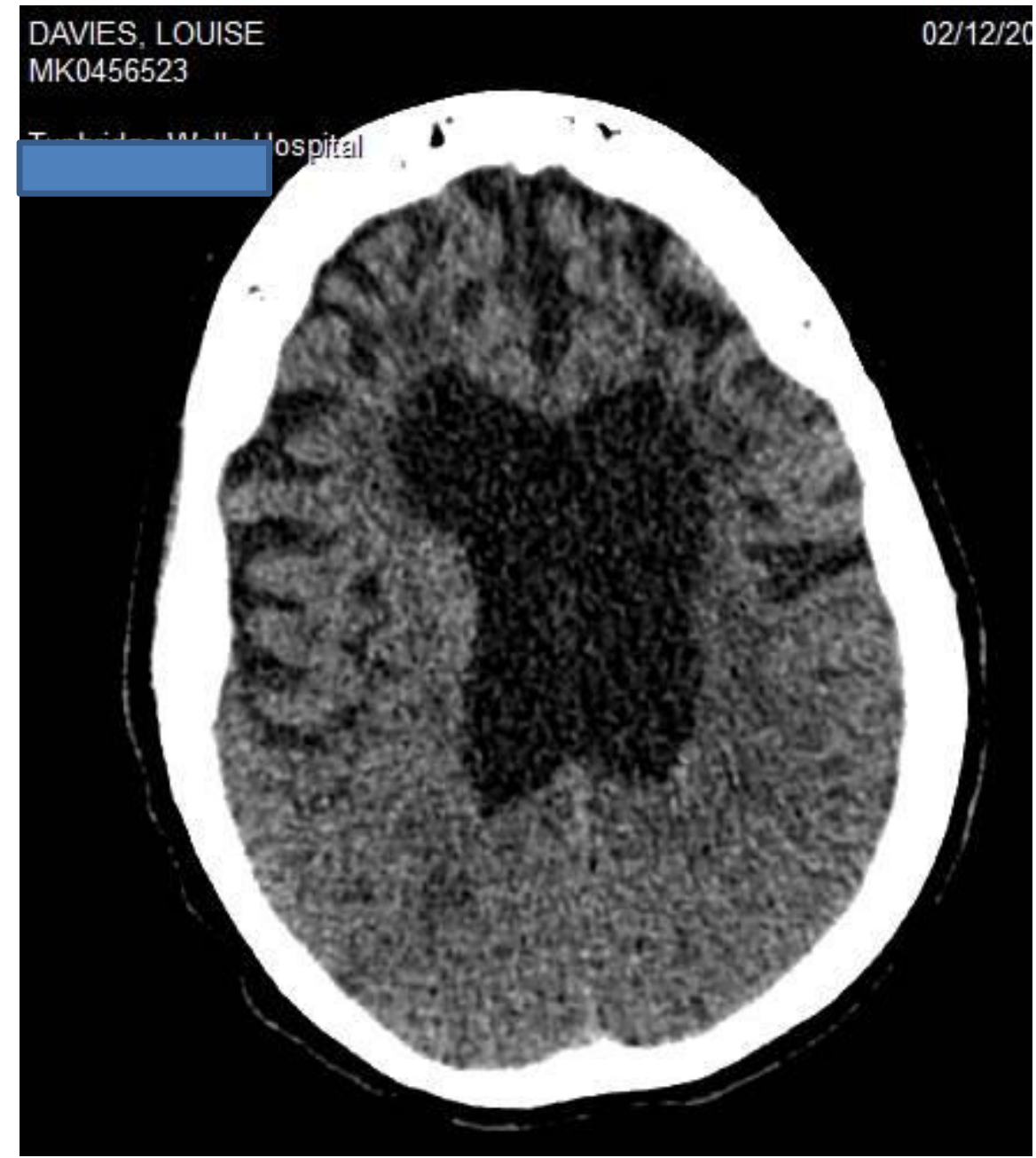

TABLE ONE A SUMMARY OF LOUISE'S WHIM ASSESSMENTS

Highest Ranked Score Total Number of Behaviours

\section{Date}

2012

52 (1 or 2 gestures)

37

2013

43 (smiles)

24

2014

43 (smiles)

21

2015

14 (mechanical vocalisation) 8

2016

14 (mechanical vocalisation) 7

